\title{
Aligning conservation and development goals with rural community priorities: capacity building for forest health monitoring in an extractive reserve in Brazil
}

\author{
$\underline{\text { Sabina C. Ribeiro }}_{9}^{1}, \underline{\text { N. Galia Selava }}^{2}, \underline{\text { Stephen G. Perz }}^{3}, \underline{\text { Foster Brown }}^{4,5}, \underline{\text { Fernando A. Schmidt }}^{1,6}, \underline{\text { Richarlly C. Silva }}^{7,8}$ and $\underline{\text { Fiama }}^{\text {Gimat }}$ \\ $\underline{\text { Lima }}^{9}$
}

\begin{abstract}
Rural communities are important stewards of forests that provide valuable ecological services. This makes them vital allies to outside organizations seeking to support conservation and development initiatives. However, rural communities also have priorities and needs that may not align with the goals of conservation and development projects. This makes effective engagement of communities by outside organizations an important challenge. When rural communities lose traditional livelihood options, they prioritize economic benefits as a condition for participating in projects, and they exhibit "project fatigue" when many projects are imposed on their time. We reflect on our experience in seeking to align the goals of a conservation and development project with community priorities in the Chico Mendes Extractive Reserve in Acre, Brazil. Our project featured capacity building for monitoring forest health to foster participation in payments for ecosystem services programs. Although we pursued prior consultations and designed participatory activities, and although we combined knowledge transmission with skills training, participation declined. That prompted our team to consult with community members, which generated important insights about expectations of immediate economic remuneration, community political cultures, communicative practices, and differences among local constituencies. These insights motivated adaptation of our practices via several strategies, such as focusing on young adults and holding workshops as part of community assemblies, which aligned project goals with the priorities of community members to improve project outcomes.
\end{abstract}

Key Words: Amazon; capacity building; community; conservation; development; environmental monitoring; forests

\section{INTRODUCTION}

In the tropics, a significant proportion of forested lands are managed by indigenous groups and other rural communities (Naughton-Treves and Wendland 2014). Such groups historically depended on standing forests for their livelihoods, which has driven research on the sustainability of community resource management (Zarin et al. 2004, Colfer 2005). However, forest management is changing because of shifts in market prices, development policies that encourage activities that degrade or remove forests such as logging, mining, and ranching, and the advance of new infrastructure (Hajjar et al. 2011, Cossio et al. 2014). Consequently, forest health is under threat because of deforestation and degradation, which negatively impact biodiversity and provision of ecosystem services (Malhi et al. 2008, Garda et al. 2010, Trumbore et al. 2015). Deforestation and forest degradation account for approximately $25 \%$ of global carbon emissions, which contribute to climate change (Davidson et al. 2012, Lovejoy and Nobre 2018).

These threats have prompted initiatives for the active participation of rural peoples in monitoring forest health (Schwartzman and Zimmerman 2005, Oldekop et al. 2012, Marion et al. 2016). The assumption is that if rural people actively contribute to scientific evidence about forest health, they will then take steps to improve and sustain it. Such steps could include sustainable harvesting of forest products, which would conserve biodiversity and ecosystem services.
Community monitoring programs have become an important tool of payments for ecosystem services (PES) programs (e.g., Skutch 2011, Dougill et al. 2012, Murthy et al. 2017). Community monitoring of forests in PES programs can contribute to forest health by supporting local livelihoods via carbon payments for conserving forests. Engaging communities in monitoring activities can be beneficial in terms of social equity and forest governance, while also reducing the cost of monitoring (Donoghue and Sturtevant 2008).

Monitoring forest health involves a set of activities that include inventories of vegetation and fauna, checking natural regeneration, measuring tree mortality and necromass, and evaluating carbon stocks and dynamics (e.g., Trumbore et al. 2015, Lausch et al. 2016). To obtain useful results, it is important to develop protocols that ensure accurate and consistent results. The need for technical data as documentation of the state of forest health poses challenges to community forest monitoring. The technical nature of monitoring protocols requires training of local peoples, which takes time, as can monitoring activities themselves.

Many rural communities face challenges to their livelihoods and are therefore preoccupied with economic difficulties (Duchelle et al. 2014a, Wunder et al. 2014). The competing demands on the limited available time among community members can undermine local interest in participating in environmental monitoring programs such as those focusing on forest health. It

\footnotetext{
${ }^{1}$ Centro de Ciências Biológicas e da Natureza, Universidade Federal do Acre, Acre, Brazil, ${ }^{2}$ Ecology and Conservation, Santa Cruz, Bolivia, ${ }^{3}$ University of Florida, ${ }^{4}$ Woods Hole Research Center, USA, ${ }^{5}$ Federal University of Acre, ${ }^{6}$ Universidade Federal do Acre, Programa de PósGraduação em Ecologia e Manejo de Recursos Naturais, ${ }^{7}$ Associação SOS Amazônia, ${ }^{8}$ Instituto Federal de Educação, Ciência e Tecnologia do Acre, ${ }^{9}$ SOS Amazônia
} 
is crucial to present the social and economic benefits of capacity building for forest monitoring as a way to synergize forest conservation and community priorities concerning livelihoods. This allows rural communities to make informed decisions about the value of forest monitoring and forest health, for forests and community livelihoods.

The Brazilian state of Acre, located in the southwestern Amazon, has long been regarded as a prominent policy laboratory for sustainable development initiatives (Kainer et al. 2003, Schmink et al. 2014). This includes the implementation of PES projects (Duchelle et al. 2014b). Acre includes a diverse array of protected areas, including sustainable use areas, the most emblematic of which is the Chico Mendes Extractive Reserve (CMER; Governo do Estado do Acre 2010). Extractive reserves aim to protect traditional livelihoods that depend on forest management and extraction of nontimber forest products (NTFPs; e.g., Allegretti 1990, Fearnside 1992). The CMER harbors NTFPs including Brazil nuts and rubber, which were key justifications to protect forests in the region (e.g., Vadjunec and Rocheleau 2009).

However, the situation has changed dramatically since the establishment of the CMER in the 1980s (e.g., Fantini and Crisóstomo 2009, Duchelle, et al. 2014a, Maciel et al. 2014). Prices for rubber have fallen, and Brazil nut productivity has varied widely, reducing the economic benefits for local peoples, who are reconsidering forest culture and looking for other livelihood activities. As a result, forests in the CMER are being cleared, mostly for livestock (Pantoja et al. 2009, Vadjunec et al. 2009, Gomes et al. 2012). Communities in the CMER therefore prioritize partnerships that can bring them economic benefits. This carries the key implication that projects focusing on conservation goals are increasingly resisted by CMER communities.

It is thus a challenge to engage rural communities with projects that seek to reconcile conservation and development via forest monitoring for PES programs. Although forest monitoring is instrumental for participation in PES programs, and although PES programs bring the promise of new income streams, the priorities of CMER communities imply that projects need to bring economic benefits. It is therefore important to design projects that incorporate activities that permit material benefits to local peoples.

We therefore designed a capacity-building program to implement a forest health monitoring program with CMER communities as a means of aligning multiple goals. Our approach was to train people in the use of technologies that involve skills not only necessary to participate in monitoring forest health, but which are also valuable in the job market. Hence while our focus was on supporting a forest monitoring program, the value of the training had applications to information management, a valued skill set in urban labor markets. At the same time, training in forest monitoring helped participants in rural communities to identify the linkages between forest health and local livelihoods and global climate. This allowed participants to quantitatively relate carbon stored in biomass to potential incomes from PES as a component of local livelihoods.

Capacity building however raises questions about exactly how to proceed in a way that respects local priorities while aligning them with conservation and development goals. There are established literatures on capacity building as related to community-based natural resource management (CBNRM), environmental education platforms, and participation in PES programs. We begin by reviewing previous work on capacity building with regard to this literature. We then offer a methodological account of our training program and its underlying strategy of aligning conservation with rural community priorities. Our findings encompass three key elements: (1) challenges that emerged in engaging rural communities in conservation and development projects, (2) adaptive strategies we adopted to address the challenges by better aligning project goals and local priorities, and (3) outcomes of the adaptive strategies. We conclude with recommendations for future conservation and development projects with rural communities.

\section{BACKGROUND}

Building capacity in rural communities for forest health monitoring brings together previous work on CBNRM, environmental education platforms, and PES programs that involve local peoples. Below we discuss each in turn, noting specific challenges that are relevant to the issues we will raise in our case study.

\section{Community-based natural resource management}

In light of criticisms of state-based and market-based approaches to conservation and development, proposals to recognize the value of CBNRM emerged in the 1990s (e.g., Berkes 1989, Western and Wright 1994). CBNRM called attention to the assets of local, traditional, and indigenous resource management practices. In particular, CBNRM highlighted the value of traditional ecological knowledge in contrast to top-down approaches imposed by the state or price-based mechanisms sometimes exploited by foreign corporations (Brosius et al. 2005, Menzies 2006). Local communities were seen as responsible stewards of natural resources because they had deep, detailed knowledge stemming from long-term management experience, and because they relied on sustainable management practices for their livelihoods.

Although there was certainly validity to such arguments, the picture that emerged from research proved to be more complex (e.g., Agrawal and Gibson 1999, Dressler et al. 2010). If communities have the assets of deep knowledge and management experience, they are also characterized by inequalities and conflicts among families, which violates assumptions about social harmony and can hinder collective decision making about resource management (Agrawal and Gibson 1999, Pulhin and Dressler 2009). Communities are also not independent of larger economies and polities, such that some local people may agree to give outside organizations access to natural resources in return for a portion of the largesse, regardless of the sustainability of the resulting activities. Such observations have driven further conceptual development and reflections on governance of natural resources in rural communities (Agrawal 2007, Doherty and Schroeder 2011, Gabay and Alam 2017, Sikor et al. 2017).

Participatory research with communities in the Amazon and elsewhere has drawn attention to the need to find ways to recognize local voices in communicating the value of CBNRM while also identifying local needs for training, market access, and 
other priorities (Kainer et al. 2009, Shanley and López 2009). This has led to more collaborative approaches with communities to combine local ecological knowledge with economically viable and environmentally sustainable resource management (e.g., Gómez-Baggethun et al. 2013, Ruiz-Mallén and Corbera 2013). A key element of such efforts has thus been to identify educational platforms that valorize community experience and knowledge while providing the means for communities to sustain resources and improve their livelihoods.

\section{Environmental education platforms}

Conservationists and educators have developed a large suite of platforms for environmental education (Jacobson et al. 2015, Monroe et al. 2019, Thomas et al. 2019). These platforms include traditional classroom instruction, various hands-on activities (games, field trips, etc.), using the arts (exhibits, theatre, music, etc.), outreach (service learning, participatory research, etc.), and others. Such platforms afford application of different theories of learning to generate results including skill acquisition and changes in attitudes and behaviors regarding conservation. The diversity of platforms means that there are many options for reaching different audiences, whether young people in school, government technical staff, company employees, rural communities, urban populations, online communities, and many others. Similarly, the diversity of platforms permits a range of teaching and learning dynamics, most of which are highly interactive. As a reflection of the diversity of platforms, the specific outcomes of environmental education also cover a broad range that is adaptable to stakeholder priorities (Jacobson et al. 2015, Thomas et al. 2019).

Environmental education in rural areas of developing countries pursues conservation goals in a context distinct from those found in urban centers and developed countries. Local peoples in rural and developing areas often rely directly on natural resources, which makes environmental questions especially salient for economic reasons as well as conservation. Further, whereas constituencies in rural and developing areas often have somewhat less formal education, they often have more environmental knowledge stemming from direct experience. Working on-site with local stakeholders is thus very valuable, but requires recognizing their distinct priorities and unique knowledge funds (e.g., Low et al. 2009, Mishra et al. 2017, Tomich et al. 2019). It thus becomes crucial for outside educators to take time to learn the local history (including past relations with outsiders), the economic basis of resource management practices, and the resulting needs and priorities tied to access to technology and markets.

These considerations bear implications for the assumptions behind the goals, approaches to learning, and platforms for environmental education. The specific priorities and needs of constituencies in rural and developing areas has motivated placebased approaches to environmental education that seek to highlight local knowledge as a point of departure for conservation initiatives (e.g., Haywood et al. 2016, Newman et al. 2017, Cruz et al. 2018). In a similar vein, environmental education in rural and developing areas underscores the importance of working to produce environmental leaders among local peoples (cf. Erhabor 2018, Sullivan and Syvertsen 2019).

\section{Payments for ecosystem services and local communities}

A key opportunity to combine environmental conservation with rural economic benefits concerns educational outreach to prepare landowners and communities to participate in PES programs. Recognition of market-based mechanisms to promote conservation has led to development of PES programs in many countries (e.g., Braat and de Groot 2012, Gómez-Baggethun et al. 2013). A prominent example is reducing emissions from deforestation and degradation (REDD+, https://www.un-redd. org/), which seeks to mitigate forest loss and degradation by pricing carbon in biomass (Kinzig et al. 2011).

A key challenge in PES programs concerns the ability of governments and banks to include small landholders and local communities (e.g., Dougill et al. 2012). The institutional requirements for participation in PES are significant: landholders must have definitive titles to their lands, and banks and governments must have institutional mechanisms for transferring funds when issuing payments (Dougill et al. 2012, To et al. 2012). The transaction costs of working with many small landholders or local communities are higher than when working with a few large private landholders. This has led to critiques of marketbased approaches to conservation such as PES programs for being exclusive of the rural poor (cf. Sullivan 2009, Martinez-Alier 2014, Pokorny and Pacheco 2014). Rural communities of small landholders often face special needs and challenges tied to the timing of payments and other key elements of the design of PES programs (e.g., Randrianarison et al. 2017).

The challenges of including rural communities in PES programs has called the attention of researchers working on CBNRM as well as environmental educators. PES programs potentially serve a vitally important social function insofar as they offer a new income stream for relatively poor populations, complementing their extant livelihoods. But the unique nature of PES programs, focused as they are on monitoring, reporting, and validation (MRV) activities as distinct from more traditional CBNRM livelihood activities, means that local peoples may be hesitant or even suspicious of PES schemes. PES programs are also founded on scientific knowledge about carbon dynamics in the global climate system, which requires some explanation for local peoples, who may have their own experience of climate change. Hence there is a need for up-front educational efforts that take account of extant CBNRM practices as well as local understandings of climate change, carbon dynamics, and ecosystem services if rural communities in developing regions are to exhibit the capacity to effectively participate in PES programs.

\section{Local communities and monitoring forest health in PES programs}

Because healthy forests are essential for ecosystem services, it is important for PES program participants to understand the capacity of forests to provide services such as carbon sequestration (Sugden et al. 2015). That requires arriving at a shared understanding by local people and PES program administrators on the status of elements of forest health, including tree growth and yield, the availability of timber and NTFPs, the quality of wildlife habitat, and cultural and scenic values (Trumbore et al. 2015). Monitoring forest health usually requires long-term records that establish forest conditions in terms of their historic ranges of variation (Alfaro et al. 2010). 
Fig. 1. Community associations for workshops in the Chico Mendes Extractive Reserve in Acre, Brazil.

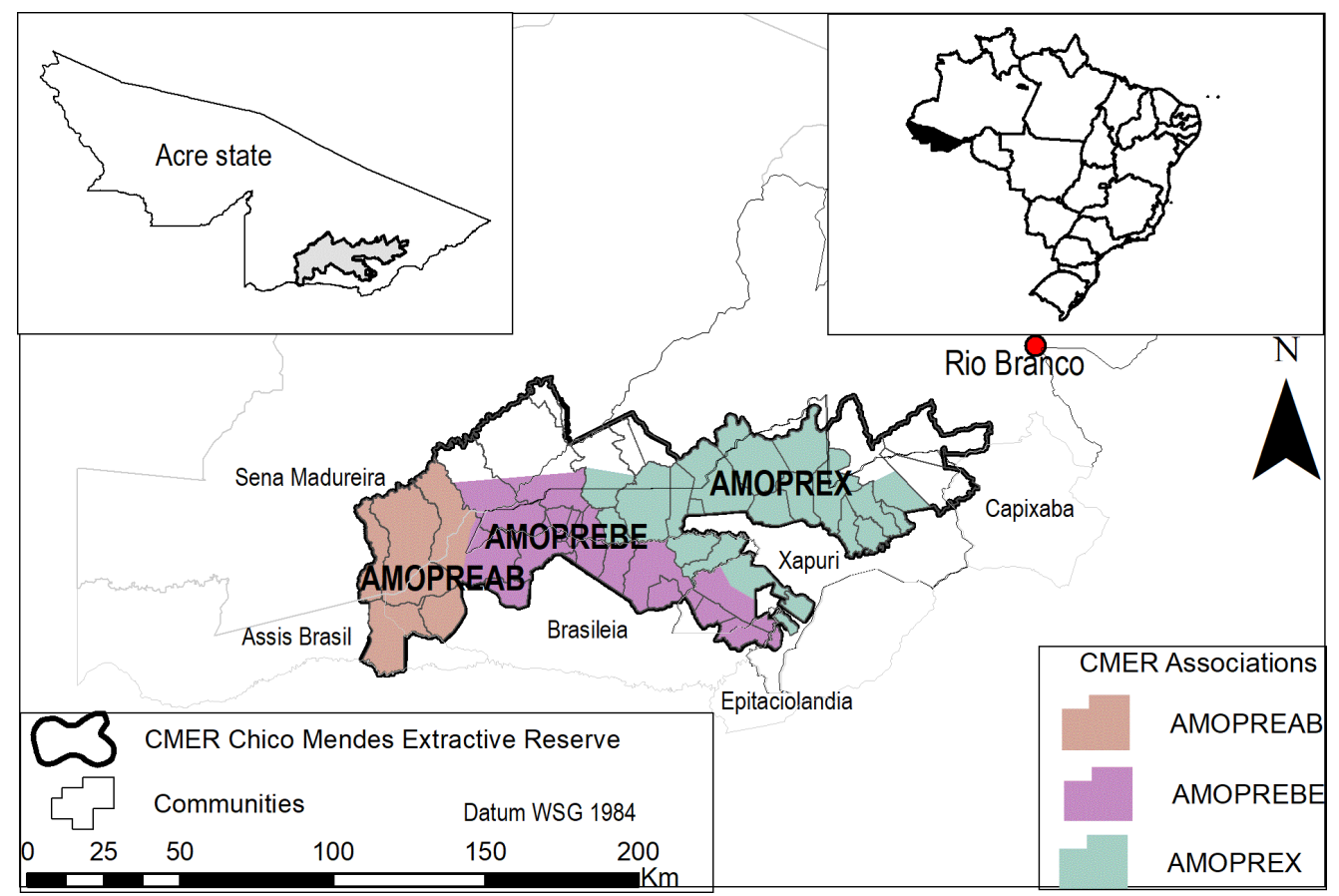

In this context, rural communities can play an important role in monitoring forest health. Just as communities stand to receive economic benefits from PES programs, they also have local knowledge of value to MRV for PES. Because they live nearby and manage forests, they empirically perceive how forests change through time.

Nonetheless, technical training is necessary to quantify these changes in a reliable way that is required of MRV in PES programs. This makes training instrumental to skills acquisition for effective participation in PES. Such training may focus on procedures such as documenting forest structure and composition via inventories, and involves learning to use technologies such as GPS, spreadsheets, and other tools. Training for forest monitoring thus creates the conditions for rural communities to benefit from PES programs as an income stream while also equipping participating community members with skills relevant to urban employment. Such capacity building synergizes initiatives for forest conservation with community priorities to generate new income opportunities.

This raises questions about how best to engage rural communities with such proposals in ways that communities find valuable, so that they fully own the process and its benefits, in both environmental and economic terms. Although this strategy might sound logical and attractive, the details of the process of engagement deserve particular attention, as well as practices for managing community responses. We devote the remainder of this article to a discussion of these issues based on our experience with a forest health monitoring program that featured capacity building in communities in the Chico Mendes Extractive Reserve (CMER) in the Brazilian state of Acre (Fig. 1).

\section{MATERIALS AND METHODS}

The CMER covers an area of 970,570 ha, divided into 46 seringais (originally known as rubber estates), each of which is divided into a number of colocações (areas where individual households traditionally harvested rubber; Governo do Estado do Acre 2010). The CMER currently has approximately 2000 families and a population close to 10,000 people. Households in the CMER are organized into five producer associations, with roughly one for each of the municipalities that share the CMER: Brasiléia, Epitaciolândia, Xapuri, Assis Brasil, Capixaba, Rio Branco, and Sena Madureira (WWF 2015).

Because of the large area of the CMER, we sought to identify selected communities that were interested in building capacity for forest monitoring. We initially aimed to involve members of all of the CMER producer associations. To that end, we consulted the Chico Mendes Institute for Biodiversity Conservation (Instituto Chico Mendes de Conservação da Biodiversidade, ICMBio), which is part of Brazil's Ministry of Environment and is responsible for overseeing federal reserves. ICMBio arranged meetings with representatives of CMER associations to present our project and discuss strategies on how to mobilize community members to participate.

The communities that showed interest in capacity building for forest monitoring were those from Xapuri, Assis Brasil, and Brasiléia. We asked the presidents of each of those associations (AMOPREX in Xapuri, AMOPREAB in Assis Brasil, and AMOPREBE in Brasiléia and Epitaciolândia) to select community members to participate in the capacity building activities following two criteria. First, we strove for inclusiveness, i.e., to include different constituencies of each association, 
notably to ensure participation by women and members of different age groups. Second, we sought participants with literacy and numeracy, which are essential skills for documenting forest health for MRV in PES programs. We prioritized these criteria as part of our capacity-building strategy to identify individuals who could subsequently serve as capacity multipliers. Literate and numerate community members would not only be capable of achieving competency in the methods for monitoring forest health, but a diverse group of trainees could in turn reach various constituencies among other community members to instruct them in the use of the same methods.

With the participants selected, we pursued a participatory strategy for building capacity in community forest monitoring (Davis Case 1990, Brown et al. 2001, Kumar 2002, Pramova and Locatelli 2013). We organized a series of workshops. The first workshop focused on the presentation of our project goals, noting how our project could help CMER communities, and what was expected from the participants. Subsequent workshops focused on implementation of practical activities to train the participants by doing. The hands-on learning activities allowed participants to directly gain knowledge of the importance of forest health and thereby acquire skills to document vegetation characteristics. Later workshops included a field orientation in the use of scientific instruments such as compasses and GPS (second workshop), a practicum on the basics of forest ecology and principles guiding botanical identification (third workshop), basic concepts to be measured in the RAINFOR protocol (http:// www.rainfor.org/en/manuals/in-the-field) for botanical inventories (fourth workshop), the specific methods for establishment of permanent forest monitoring plots using the RAINFOR protocol (fifth workshop), and the use of tools and techniques for analysis of vegetation data (sixth workshop). These workshops thus featured training on the use of scientific instruments, which provided foundations for documenting vegetation characteristics. Combined with skills training in forest inventories, those tools allow for applications in monitoring forest health, among other purposes.

The steps for preparation of each workshop included (1) development of curricular materials, (2) mobilizing community members, and (3) coordination of field logistics, e.g., transport, location, and workshop agendas. The materials we used included a methodological roadmap, presentation slides, and instruction manuals. Those materials supported interactive presentations and activities for the assimilation of knowledge and practice of skills. The methodological roadmap served as a guide to the sequence of activities we implemented during a workshop. Presentations illustrated the conceptual content and practical activities. Manuals for activities provided supporting material to train community members to practice key skills. Every workshop participant received an activities manual. The interactive dynamics were essential to engage community members as active participants by ensuring that they had numerous opportunities to share their experiences related to the knowledge and skills on which we focused.

We invited the participants one month prior to the day scheduled for a workshop. This was to leave time to disseminate invitations because our key performance indicator for the workshops was the number of participants. Our initial target for participation was
20 community members per workshop. To manage invitations, we first contacted the presidents of the participating associations. For later workshops, we sought to contact previous participants directly to ensure that they were aware of the next workshop. However, most CMER residents live in areas with difficult access by vehicular traffic and with limited means of communication. Therefore, we primarily communicated with association presidents and community members when they were in the towns near the CMER.

Workshops were usually two days in length, and occurred during weekends because most community members had to work in their colocações during the week. The workshops were held in the town of Xapuri (first and second workshops), at the Rio Branco campus of the Federal University of Acre (UFAC; third, fourth, and sixth workshops), and inside the CMER in Assis Brasil (fifth workshop). In each workshop, project funds covered the costs of transportation, accommodation, and food for participants.

After the six capacity building workshops, we pursued two additional events (seventh and eighth workshops) to train participating community members in the preparation of their own workshops, which would focus on dissemination of what they had learned. The seventh and eighth workshops thus supported the participants in their training as capacity multipliers, preparing them for instructing other community members in the methods and tools of forest monitoring. The dissemination training workshops were held at UFAC with the participation of community members from the CMER associations of Xapuri (AMOPREX) and Assis Brasil (AMOPREAB). During the dissemination training workshops, we supported the participating community members in defining the aim of their dissemination workshops. This involved discussions of the materials required, the sequence of themes to be presented, and the logistics (location, date, and mobilization).

After training, participants then held dissemination workshops in two locations inside the CMER. The first location was Xapuri, and the other was Assis Brasil. In each dissemination workshop, we also measured performance in terms of the number of participating community members. The Xapuri dissemination workshop was one day long and was held in a rural school inside the CMER. Three community members from AMOPREX prepared and conducted the dissemination workshop. The Xapuri CMER community coordinator and the three trained disseminators shared their experiences. This mobilization involved conversations and distribution of pamphlets with the date and location of the workshop. The Assis Brasil dissemination workshop was a one-day event held during the 13th Assembly of the AMOPREAB in the headquarters of AMOPREAB. Three community members from AMOPREAB prepared and conducted the workshop.

The dissemination workshops at Xapuri began with introductions of participants followed by an icebreaker game. Then the organizers prompted community members to report their perceptions about forest health and changes in forests. After that discussion, there was a presentation about the concept of forest health and the skills acquired by the community disseminators related to documentation of vegetation characteristics. Disseminators also devoted attention to the issue of climate change and the specific changes observed in the region, such as 
Fig. 2. Challenges and recommendations for engaging rural communities in conservation and development projects.

\begin{tabular}{|c|c|c|}
\hline \multicolumn{3}{|c|}{ CAPACITY BUILDING FOR FOREST HEALTH MONITORING } \\
\hline \multicolumn{3}{|c|}{ CHALLENGES } \\
\hline Community political cultures and practices & Logistics to access communities & Managing expectations \\
\hline $\begin{array}{l}\text { Engage } \\
\text { participants }\end{array}$ & $\begin{array}{l}\text { Unpaved roads } \\
\text { and trails }\end{array}$ & $\begin{array}{l}\text { Immediate } \\
\text { remuneration }\end{array}$ \\
\hline \multicolumn{3}{|c|}{ RECOMMENDATIONS } \\
\hline Community political cultures and practices & Logistics to access communities & Managing expectations \\
\hline $\begin{array}{l}\text { Design a project that attends to proponent goals and } \\
\text { community priorities and needs }\end{array}$ & $\begin{array}{l}\text { Organize workshops inside communities during the } \\
\text { dry season, and in towns during the rainy season }\end{array}$ & $\begin{array}{l}\text { Allocate part of project budgets for remuneration of } \\
\text { community members for their participation }\end{array}$ \\
\hline $\begin{array}{l}\text { Avoid relying on state agencies or association } \\
\text { representatives to mobilize community members }\end{array}$ & $\begin{array}{l}\text { Careful planning of workshops, considering multiple } \\
\text { options to manage access and cancellations }\end{array}$ & $\begin{array}{l}\text { In capacity building, include the transmission of } \\
\text { skills important to community needs and priorities }\end{array}$ \\
\hline $\begin{array}{l}\text { Incorporate project activities into community } \\
\text { events to reach more poople, including women }\end{array}$ & $\begin{array}{l}\text { Identify key community members that can help in } \\
\text { organizing the workshops }\end{array}$ & $\begin{array}{l}\text { Focus capacity building on young people who are } \\
\text { interested in skills acquisition; future leaders }\end{array}$ \\
\hline
\end{tabular}

severe floods, droughts, and forest fires. The workshop ended by dividing the participants into working groups, in which organizers gave participants guiding questions and participants debated possible solutions for the problems that affect forest health inside the CMER.

At the Assis Brasil workshop, the process began with individual introductions of the community disseminators. Because of the large number of participants, there was not time for introductions of other attendees or an icebreaker game. But similarly to the dissemination workshop at Xapuri, there was a presentation about forest health and the methods and tools for documentation of vegetation characteristics. Afterward, disseminators divided participants into groups and they discussed possible community responses to climate change and extreme events that have been occurring in the CMER. The workshop ended after each group presented their perceptions.

\section{RESULTS}

Having outlined our initial strategy and methods, we now focus on the challenges we encountered in working with local peoples in the CMER. Although our process was highly consultative in terms of identifying local authorities to indicate potential participants, and although the workshops were participatory in terms of hands-on activities that featured skills acquisition, we encountered several challenges, many of which were unexpected. The unexpected challenges stemmed from the preoccupation of CMER residents with identifying new income streams, and project fatigue from having participated in various workshops without immediate economic benefits. We therefore center our attention not on logistical challenges as much as on challenges stemming from the difficult circumstances facing the rural communities with whom we sought to work. In that context, we feature three main challenges: (1) understanding community political cultures and practices; (2) logistics to access communities in the CMER; and (3) managing expectations of community members. For each, we discuss three key elements of our findings. First, we note the particulars of the challenge itself. Second, we discuss the strategies we pursued to adaptively align our project goals with the priorities of rural communities. Third, we discuss the results we gained from application of our adaptive strategies. We summarize our findings in an infographic, which appears in Figure 2.

\section{Understanding community political cultures and communication practices}

The first challenge we faced was to find an effective means to engage CMER community members so they would be interested in participating in our project. This required a learning process on our part. Our initial approach was to go through ICMBio, which arranged a meeting with association representatives. This seemed to us a natural path to engage community members because ICMBio regularly works with CMER communities.

However, the result was not what we expected. First, only three of the five producer associations showed interest in participating in our capacity building activities (AMOPREX in Xapuri, AMOPREAB in Assis Brasil, and AMOPREBE in Brasiléia and Epitaciolândia). Further, community members from AMOPREBE gradually stopped participating in the workshops. Consequently, they did not participate in the dissemination training workshops and did not hold any of their own dissemination workshops. 
Representatives of AMOPRESENA (Sena Madureira) and AMOPRECARB (Capixaba and Rio Branco) noted that it was difficult for their members to travel from the CMER because of difficulties with travel logistics and because their livelihood activities in the forest did not allow time to leave. This indicated that previous commitments by community members, often linked to their livelihood activities, still stands as a key logistical impediment to their participation in projects.

Second, participation was inhibited by limited communication among CMER community members. Whereas some association leaders indicated up front that their members would have difficulty in participating, we also found out later that some community members who were interested in our project were not told about our workshops. For example, during the dissemination workshops in Xapuri and Assis Brasil near the end of our project, several participants mentioned they did not know about our project and that they wanted to participate in the capacity building activities, which had unfortunately already concluded.

We realized that our initial strategy to mobilize community members by going through formal institutions was not very effective in reaching people in rural communities. That in turn revealed how CMER communities function and how local leaders wield power. We realized that association representatives had somewhat limited power to mobilize the communities they represent. This was due to a combination of difficulty in reaching people and lack of personal interest working with those who are not their political supporters. Consequently, the participants in our capacity building activities tended to come from the inner circle surrounding association representatives.

As a result of the politics of communication in CMER communities, we only came to understand the perspectives of a nonrepresentative subset of members who participated. Importantly, we came to that realization during the later workshops. By then, it was not possible to include other community members in the project because we had already finished the capacity building activities. We thus learned important lessons about community political cultures as well as their communication practices. It was not sufficient to rely on state agencies or association representatives, because the first does not have broad access to community members, and the second lacks universal support of the communities they represent. These are significant challenges, not only to conservation and development projects, but also to governmental agencies that follow the path of communicating with community leaders in their outreach.

A third aspect to the challenge of understanding how CMER communities function concerns the problem of social isolation. Living deep inside the forest can greatly impede communication among people even if they desire to be in contact. Some families live in remote locations to be near relatives. This is an additional challenge that projects need to overcome. Many households have access to radios, which do permit dissemination of announcements for events, but most radios only permit one-way communication. Other households have family members with cell phones, but tree canopies and lack of cell coverage present difficulties to communication.

The issue of social isolation is highly gendered in the CMER. Schmink and Arteaga Gómez-García (2015) note that in many rural communities in the Amazon, women tend to spend more time around the homestead and thus live in relatively isolated social circumstances. At the same time, our experience with communities in the CMER is that women were often more interested than men in participating in project activities. Hence the gendered nature of rural isolation particularly impeded participation in our project by a key constituency that was especially disposed to participate. As with other challenges of working with communities in the CMER, we did not fully appreciate this difficulty at the outset.

That said, our funder, the U.S. Agency for International Development (USAID), prioritized gender balance among participants in project activities. Consequently, in our interactions with CMER association representatives, we pursued the strategy of requesting participants with a balanced representation of men and women. In the event, we achieved a more or less balanced gender composition in our project workshops. Importantly, our strategy required that up-front communications explicitly recognized the challenge of social isolation as a gender issue. It was crucial to underscore the importance of gender balance in the representation of community members to ensure equitable participation of women and men in workshops. Although gender has been highlighted as a vital dimension of conservation and development in the Amazon (Schmink and Arteaga GómezGarcía 2015), an up-front strategy about gender was necessary to ensure gender-balanced participation.

\section{Logistics to access communities in the CMER}

Although social isolation is gendered, difficult access greatly affects everyone in families that live farther inside the CMER. The roads and trails inside CMER are unpaved, and not maintained for year-round use. During the rainy season (OctoberApril), when there are consecutive rainy days, it is almost impossible to get into or out of the CMER, even using motorcycles or four-wheel-drive vehicles. The limited transport infrastructure and rigorous climatic conditions thus imposed logistical challenges to our ability to reach some communities in the CMER.

The seasonality of precipitation limited the period during the year in which we could schedule a workshop, as we had to hold them during the dry season. We therefore pursued a strategy of organizing workshops during the dry season, and in towns during the rainy season. Of the 10 workshops we offered, six occurred during April-July (four in Rio Branco, one at Xapuri, and one in the CMER). The remaining four workshops happened between October and December and February, with one in Rio Branco and three inside the CMER. In the case of the latter, we only knew for sure on the eve of the scheduled day if the workshop would occur, because that depended on trail conditions based on rainfall intensity in the previous days.

Additionally, we experienced institutional difficulties in accessing a four-wheel-drive vehicle to gain access to the interior of the CMER. The rent price of this kind of vehicle in the region is very high, around US\$120 per day. Because of the high price, we preferred to use a truck from UFAC, but that was frequently unavailable or its four-wheel drive was broken. The alternative was to travel in an economy car to the town closest to the point of entry into the CMER, and then hire a freight truck to take us inside. These logistical complications required substantial time for planning while also being prepared with an alternative plan. 
Collaborative projects in the Amazon are thus impeded by climatic seasonality and difficult trail conditions, which can greatly hinder planning of events with rural communities. Even as we engaged in a practice of preparing "plan A," understanding that we needed a "plan B," access was never guaranteed, especially in the rainy season. This in turn posed challenges to managing expectations of communities who took time out of their busy lives to attend a workshop.

\section{Managing expectations of CMER community members}

Most members of CMER communities dedicate substantial time to livelihood activities in fields and forests. For them, participating in conservation and development projects means that they must interrupt their daily activities and, in some cases, lose money. Given that trade-off, some community members expect to receive money to participate in project activities. Those community members view payments for time spent in project workshops as compensation for listening to lectures or learning new practices.

A related issue concerns project fatigue by CMER community members. Over the years, state agencies, NGOs, and universities have brought various conservation and development projects intended to support communities in the CMER. At the same time, the narrowing of livelihood options in the CMER has prompted communities to prioritize economically beneficial projects. When projects do not come with concrete economic benefits, this proves frustrating for community members. Some are therefore reserved and dubious about participating in new projects, as members increasingly prioritize and thus expect assurances about economic benefits.

We encountered such expectations in our first workshop. After we presented our project goals, we opened a space for dialogue with community members about their needs and priorities. Participants then asked if they would receive money for participating in the capacity building activities for forest monitoring. We replied that the project did not have any financial resources available to pay participants, but that they would receive knowledge and skills. As outlined in our methods, we prepared a capacity-building program that focused on forest monitoring for PES programs by featuring skills training in the use of information technology that is relevant to procuring jobs in the urban labor market. This reflected our initial strategy to be responsive to known community priorities and needs with regard to economic benefits from projects.

Nevertheless, in the later workshops we noticed a reduction in the number of participants. Whereas we started with 20 community members in the first workshop, the number of participants dropped to 6-12 in later events (second to eighth). As in our first workshop, we opened a dialogue space to consult with participants, which revealed expectations about immediate economic benefits from projects. That said, the decline was selective of certain subgroups of community members. Those who continued to participate were mainly young community members (18-25 years old). This suggested that older community members, who likely had more experience with outside projects, also had less patience in waiting for economic benefits to materialize. Conversely, young people likely had less project fatigue and more interest in skills acquisition for jobs. Further, we noticed that the young participants who returned for later workshops were also emerging leaders in their communities. Our consultations during workshops revealed that those participants found great value in the project goals and the skills and knowledge on offer. During later stages of our project, we therefore adopted the strategy of tailoring our training and dissemination activities to young adults as a means of supporting their leadership before their communities.

We experienced the same phenomenon later in the project, following the initial dissemination workshop in Xapuri. The community disseminators from AMOPREX mobilized around 60 people to attend. From that, only nine people participated in the next dissemination workshop. During group discussions and in response to more informal consultations, the returning participants mentioned that people in the CMER were increasingly interested in getting immediate economic benefits to improve their living conditions. That said, all of the returning participants seemed truly interested in learning about forest health and were concerned with the future of their forests.

After these experiences, we adopted a different strategy for the dissemination workshop in Assis Brasil. Instead of relying on state agencies or association representatives to mobilize people, AMOPREAB offered to let us hold the workshop during its 13th Assembly. Association assemblies are significant events in the CMER because associations discuss issues important to community members and make decisions such as election of representatives or participation in opportunities involving new livelihood activities. Adapting our dissemination strategy by incorporating the workshop as an item in the assembly agenda consequently resulted in 70 participants. By then, we were well aware that not all community members were present because they cared about forest health. Nonetheless, the incorporation of our workshop into the assembly permitted us to reach diverse constituencies of community members. This strategy was effective in communicating basic information about our project, and called the attention of community members who did not otherwise know about our activities.

Our experience at the AMOPREAB assembly confirmed factors that hindered participation in our previous efforts. Presenting via the assembly sidestepped the limitations of depending on state agencies or individual leaders. It also helped offset the disadvantages of social isolation that differentially affected women as a key constituency. Finally, it provided exposure of the project to people otherwise disinterested in conservation and development.

In turn, using the assembly strategy for dissemination provided a vital opportunity for the disseminators as young community leaders. Because participants in earlier workshops featured young leaders, they served the valuable role of capacity multipliers by sharing what they had learned, in their own terms. This strategy offered the young leaders an opportunity to explain not only the importance of topical content like the relationship of forest health to livelihoods but also the value of the skills they had acquired, including in terms of their economic importance. It is worth noting that in a broader global context where young people are leaving rural communities and not returning, the interest of young participants in our workshops and the fact that they found value in the content and skills acquired is an important result. 


\section{DISCUSSION AND CONCLUSION}

To summarize, we implemented a conservation and development project in the CMER to engage rural communities in capacity building activities to support community monitoring of forest health. We sought to make the project highly participatory and to be responsive to community economic needs by featuring skills training. However, we experienced a decline in participation. This occurred because of logistical difficulties involving transit and communication problems, competing livelihood activities, and lack of interest in the project because it offered no immediate economic benefits.

These points motivated us to reflect on the challenges encountered. Issues of seasonality and accessibility are intrinsic challenges in the Amazon, and depend on environmental factors and state policies over which project teams and communities have little control. We therefore set those issues aside, and focus on questions of how best to manage relationships with rural communities in the context of conservation and development projects. We reflect on two intertwined issues: community demand for concrete economic benefits from projects, and the problem of project fatigue.

Our project came in the broader context of project fatigue among communities in the CMER, something our colleagues have seen in other rural communities in the study region. Gone are the days where outside organizations can go to rural communities, conduct research or workshops, and then leave. Communities have for some years required prior agreements for follow-ups to return research findings and to make recommendations for action. Our project revealed a further stage in the evolution of relationships between outside social actors and rural communities, in which community members expect a direct financial benefit for participating. Before defining the goals of a project, consultations with communities and associations about their priorities and needs are now a requirement, and those priorities and needs now focus on economic returns to participation. Although prior consultations are a well-established practice in participatory action research and various forms of extension, the issues of economic benefits and project fatigue sharpen and focus the topics that require discussion.

These requirements exist in a context where many funder calls for conservation and development projects do not have a specific budget rubric for financial resources that can be destined to community members in order to secure their participation. At the same time, results frameworks for conservation and development projects often include performance indicators for capacity building like the number of participants or people who increased their knowledge of a topic. This creates the conditions for an important contradiction, such that conservation and development projects seek to measure the effectiveness of capacity building activities in terms of scale of participation or learning while failing to provide incentives important to target populations to participate in the first place. The result of the contradiction is to undermine the impact of conservation and development projects when target populations set their own requirements to participate.

It is significant that we encountered the problem of a lack of interest in a project focusing on monitoring of forest resources to sustain forest health. These tasks are eminently relevant to participation in PES programs and similar market-based conservation instruments that hold out the potential for future economic benefits to rural peoples. For many community members, an eventual economic benefit was not good enough; it had to come as an immediate consequence of participation. Community members of the CMER argued that they are tired of capacity building activities, because the link to economic benefits is indirect or hypothetical. Hence the problem we faced is not unique to the case of capacity building for monitoring of forest health; it is likely to apply to all manner of capacity-building initiatives. In the case of CMER communities, many members were more interested in obtaining machinery and infrastructure to process NTFPs in order to increase their incomes. We certainly sought to draw the conceptual linkages from forest monitoring as a key to forest health and thus possible future payments for conservation of ecosystem services. However, the concept of ecosystem services is very abstract for some people, and very different from established livelihood activities, which hindered interest. This situation also faces REDD+ projects, in which it is necessary to explain to community members concepts such as carbon sequestration, which is an ecosystem service that is invisible, though carbon stocks are evident in forests.

In light of those challenges, we pursued strategies to adapt our project to the priorities of local communities and thereby improve the scale and quality of participation in our workshops. Those strategies proved effective, and provide the basis for recommendations out of our experience (Fig. 2). One adaptive strategy was to focus on young people, who are often still in school and more open to learning new things. Our broader recommendation from that strategy is to work to identify specific constituencies within communities that are motivated to participate for their own reasons. This, however, requires identification of constituencies who have goals that align with those of the project. In our case of a capacity-building project, young people often have had more exposure to new technologies and can in turn convey what they have learned to others in their communities, making them effective capacity multipliers. Another adaptive strategy was to broaden our communication, for we realized that some constituencies who were interested in participation, such as women, had more limited means of communication. The broader recommendation here is to pursue multiple avenues of communicating with communities, whether via leaders or particular families and other constituents. This may require some trial and error, as not all constituents are wellconnected. In our experience, it took time to realize that women were a prominent interested constituency, but reaching them required an up-front strategy. A third adaptive strategy was to incorporate project activities into association assemblies. From this comes the larger recommendation to situate project activities in pre-established routines of community members, notably meetings and conferences they find important. This of course requires some negotiation with community representatives. In our experience, the strategy was eminently workable, and allowed us to reach many constituencies while featuring motivated participants as presenters. We highlight these three recommendations among others because they are synergistic: we identified motivated constituencies, and employed multiple communication avenues to reach other constituencies, to support the first in reaching the second in community assemblies. 
This is not to suggest that the adaptive strategies in our project are a complete solution. There were broader structural challenges at play. In the CMER, as in other extractive reserves, community members can use land but do not retain land tenure in terms of possession. This concessional tenure status may contribute to the lack of interest in investing time in monitoring forest resources. In turn, low levels of trust between community members and their leaders, and correspondingly high levels of disempowerment and rural exodus, provide the context that could culminate with the end of functioning communities in the CMER. If that happens, there is good reason to expect massive deforestation in the CMER, as has already transpired in the surrounding landscape. Capacity building along the lines we have pursued, with support from local, state, and national governments, may yet be able to reverse this situation. However, it is necessary to act now, and that requires implementing adaptive strategies to improve engagement with rural communities in the context of their priorities and needs.

Responses to this article can be read online at: http://www.ecologyandsociety.org/issues/responses. php/11665

\section{Acknowledgments:}

The work reported was made possible by funding from U.S. Agency for International Development under the Partnerships for Enhanced Engagement in Research (PEER) program of the National Academies of Science. The coauthors thank the Chico Mendes Institute for Biodiversity Conservation (ICMBio), the leaders and participants of AMOPREX, AMOPREAB, and AMOPREBE, and the Federal University of Acre, SOS Amazonia and FUNDAPE for their support to the activities reported. The contents and interpretations in this manuscript are the responsibility of the coauthors.

\section{Data Availability Statement:}

We do not draw on a database per se, but report findings from our experiences of challenges in workshops we conducted with stakeholders. We are happy to make relevant data available to interested readers.

\section{LITERATURE CITED}

Agrawal, A. 2007. Forests, governance, and sustainability: common property theory and its contributions. International Journal of the Commons 1:111-136. https://doi.org/10.18352/ ijc. 10

Agrawal, A., and C. C. Gibson. 1999. Enchantment and disenchantment: the role of community in natural resource conservation. World Development 27:629-649. https://doi. org/10.1016/S0305-750X(98)00161-2

Alfaro, R. I., A. Battisti, A. Carroll, R. Fleming, and J. Hantula. 2010. Forest health in a changing environment. Pages 113-134 in G. Mery, P. Katila, G. Galloway, R. I. Alfaro, M. Kanninen, M. Lobovikov, and J. Varjo, editors. Forests and society: responding to global drivers of change. IUFRO World Series Volume 25.
International Union of Forest Research Organizations, Vienna, Austria.

Allegretti, M. H. 1990. Extractive reserves: an alternative for reconciling development and environmental conservation in Amazonia. Pages 252-264 in A. B. Anderson, editor. Alternatives to deforestation: steps towards sustainable use of the Amazon rain forest. Columbia University Press, New York, New York, USA.

Berkes, F., editor. 1989. Common property resources: ecology and community-based sustainable development. Belhaven, London, UK.

Braat, L. C., and R. de Groot. 2012. The ecosystem services agenda: bridging the worlds of natural science and economics, conservation and development, and public and private policy. Ecosystem Services 1:4-15. https://doi.org/10.1016/j.ecoser.2012.07.011

Brosius, J. P., A. L. Tsing, and C. Zerner, editors. 2005. Communities and conservation: histories and politics of community-based natural resource management. AltaMira, Walnut Creek, California, USA.

Brown, I. F., K. Kainer, A. S. Alexandre, and E. O. Amaral. 2001. Extractive reserves and participatory research as factors in the biogeochemistry of the Amazon Basin. Pages 122-138 in M. E. McClain, R. L. Victoria, and J. E. Richey, editors. The biogeochemistry of the Amazon Basin. Oxford University Press, New York, New York, USA.

Colfer, C. J. P., editor. 2005. The equitable forest: diversity, community and resource management. Resources for the Future, Washington, D.C., USA.

Cossio, R., M. Menton, P. Cronkleton, and A. Larson. 2014. Community forest management in the Peruvian Amazon: a literature review. Center for International Forestry Research, Bogor, Indonesia.

Cruz, A. R., S. T. Selby, and W. H. Durham. 2018. Place-based education for environmental behavior: a 'funds of knowledge' and social capital approach. Environmental Education Research 24:627-647. https://doi.org/10.1080/13504622.2017.1311842

Davidson, E. A., A. C. de Araújo, P. Artaxo, J. K. Balch, I. F. Brown, M. M. C. Bustamante, M. T. Coe, R. S. DeFries, M. Keller, M. Longo, J. W. Munger, W. Schroeder, B. S. Soares-Filho, C. M. Souza, and S. C. Wofsy. 2012. The Amazon basin in transition. Nature 481:321-328. https://doi.org/10.1038/nature10717

Davis Case, D'A. 1990. The community's toolbox: the idea, methods and tools for participatory assessment, monitoring and evaluation in community forestry. Food and Agriculture Organization, Rome, Italy.

Doherty, E., and H. Schroeder. 2011. Forest tenure and multilevel governance in avoiding deforestation under REDD+. Global Environmental Politics 11:66-88. https://doi.org/10.1162/GLEP a 00084

Donoghue, E. M., and V. E. Sturtevant, editors. 2008. Forest community connections: implications for research, management and governance. Resources for the Future, Washington, D.C., USA. https://doi.org/10.4324/9781936331451

Dougill, A. J., L. C. Stringer, J. Leventon, M. Riddell, H. Rueff, D. V. Spracklen, and E. Butt. 2012. Lessons from community- 
based payment for ecosystem service schemes: from forests to rangelands. Philosophical Transactions of the Royal Society B: Biological Sciences 367:3178-3190. https://doi.org/10.1098/ rstb.2011.0418

Dressler, W., B. Büscher, M. Schoon, and D. Brockington. 2010. From hope to crisis and back again? A critical history of the global CBNRM narrative. Environmental Conservation 37:5-15. https:// doi.org/10.1017/S0376892910000044

Duchelle, A. E., A. M. Almeyda Zambrano, S. Wunder, J. Börner, and K. Kainer. 2014a. Smallholder specialization strategies along the forest transition curve in southwestern Amazonia. World Development 64:S149-S158. https://doi.org/10.1016/j.

worlddev.2014.03.001

Duchelle, A. E., M. Greenleaf, D. Mello, M. F. Gebara, and T. Melo. 2014b. Acre's State system of incentives for environmental services (SISA), Brazil. Pages 33-50 in E. O. Sills, S. S. Atmadja, C. de Sassi, A. E. Duchelle, D. L. Kweka, I. A. P. Resosudarno, and W. D. Sunderlin, editors. REDD+ on the ground: a case book of subnational initiatives across the globe. Center for International Forestry Research, Bogor, Indonesia.

Erhabor, N. I. 2018. Developing leaders through mentoring in environmental education. Electronic Green Journal 1:1-10.

Fantini, A. C., and C. F. Crisóstomo. 2009. Conflitos de interesses em torno da exploração madeireira na Reserva Extrativista Chico Mendes, Acre, Brasil. Boletim do Museu Paraense Emilio Goeldi 4:231-246. https://doi.org/10.1590/S1981-81222009000200002

Fearnside, P. M. 1992. Reservas extrativistas: uma estratégia de uso sustentado. Ciência Hoje 14:15-17.

Gabay, M., and M. Alam. 2017. Community forestry and its mitigation potential in the Anthropocene: the importance of land tenure governance and the threat of privatization. Forest Policy and Economics 79:26-35. https://doi.org/10.1016/j.forpol.2017.01.011

Garda, A. A., J. M. C. da Silva, and P. C. Baião. 2010. Biodiversity conservation and sustainable development in the Amazon. Systematics and Biodiversity 8:169-175. https://doi.

org/10.1080/14772000.2010.484435

Gomes, C. V. A., S. G. Perz, and J. M. Vadjunec. 2012. Convergence and contrasts in the adoption of cattle ranching: comparisons of smallholder agriculturalists and forest extractivists in the Amazon. Journal of Latin American Geography 11:99-120. https://doi.org/10.1353/lag.2012.0018

Gómez-Baggethun, E., E. Corbera, and V. Reyes-Garcia. 2013. Traditional ecological knowledge and global environmental change: research findings and policy implications. Ecology and Society 18(4):72. https://doi.org/10.5751/ES-06288-180472

Governo do Estado do Acre. 2010. Zoneamento EcológicoEconômico do Estado do Acre, Fase II. Second edition. SEMA, Rio Branco, Acre, Brazil.

Hajjar, R., D. G. McGrath, R. A. Kozak, and J. L. Innes. 2011. Framing community forestry challenges with a broader lens: case studies from the Brazilian Amazon. Journal of Environmental Management 92:2159-2169. https://doi.org/10.1016/j.jenvman.2011.03.042
Haywood, B. K., J. K. Parrish, and J. Dolliver. 2016. Place-based and data-rich citizen science as a precursor for conservation action. Conservation Biology 30:476-486. https://doi.org/10.1111/ cobi. 12702

Jacobson, S. K., M. D. McDuff, and M. C. Monroe. 2015. Conservation education and outreach techniques. Second edition. Oxford University Press, New York, New York, USA.

Kainer, K. A., M. L. DiGiano, A. E. Duchelle, L. H. O. Wadt, E. Bruna, and J. L. Dain. 2009. Partnering for greater success: local stakeholders and research in tropical biology and conservation. Biotropica 41:555-562. https://doi.org/10.1111/j.1744-7429.2009.00560. $\underline{\mathrm{X}}$

Kainer, K. A., M. Schmink, A. C. Pinheiro Leite, and M. J. da Silva Fadell. 2003. Experiments in forest-based development in western Amazonia. Society and Natural Resources 16:869-886. https://doi.org/10.1080/716100619

Kinzig, A. P., C. Perrings, F. S. Chapin III, S. Polasky, V. K. Smith, D. Tilman, and B. L. Turner II. 2011. Paying for ecosystem services - promise and peril. Science 334:603-604. https://doi. org/10.1126/science.1210297

Kumar, S., editor. 2002. Methods for community participation: a complete guide for practitioners. CAB Direct, New York, New York, USA.

Lausch, A., S. Erasmi, D. J. King, P. Magdon, and M. Heurich. 2016. Understanding forest health with remote sensing, Part I a review of spectral traits, processes and remote-sensing characteristics. Remote Sensing 8:1029. https://doi.org/10.3390/ $\underline{\text { rs } 8121029}$

Lovejoy, T. E., and C. Nobre. 2018. Amazon tipping point. Science Advances 4:eaat2340. https://doi.org/10.1126/sciadv.aat2340

Low, B., S. R. Sundaresan, I. R. Fischoff, and D. I. Rubenstein. 2009. Partnering with local communities to identify conservation priorities for endangered Grevy's zebra. Biological Conservation 142:1548-1555. https://doi.org/10.1016/j.biocon.2009.02.003

Maciel, R. C., P. G. Cavalcante Filho, and E. F. Souza. 2014. Distribuição de renda e pobreza na Floresta Amazônica: um estudo a partir da Reserva Extrativista (RESEX) Chico Mendes. Revista de Estudos Sociais 16:136-153. https://doi.org/10.19093/ res.v16i32.1946

Malhi, Y., J. T. Roberts, R. A. Betts, T. J. Killeen, W. Li, and C. A. Nobre. 2008. Climate change, deforestation, and the fate of the Amazon. Science 319:169-172. https://doi.org/10.1126/ science. 1146961

Marion, P., C. Schweitzer, M. Rosenthal, V. Keuck, J. Bumberger, P. Dietrich, M. Heurich, A. Jung, and A. Lausch. 2016. In situ/ remote sensing integration to assess forest health - a review. Remote Sensing 8:471-482. https://doi.org/10.3390/rs8060471

Martinez-Alier, J. 2014. The environmentalism of the poor. Geoforum 54:239-241. https://doi.org/10.1016/j.geoforum.2013.04.019

Menzies, C. R., editor. 2006. Traditional ecological knowledge and natural resource management. University of Nebraska Press, Lincoln, Nebraska, USA. 
Mishra, C., J. C. Young, M. Fiechter, B. Rutherford, and S. M. Redpath. 2017. Building partnerships with communities for biodiversity conservation: lessons from Asian mountains. Journal of Applied Ecology 54:1583-1591. https://doi.org/10.1111/1365-$\underline{2664.12918}$

Monroe, M. C., R. R. Plate, A. Oxarart, A. Bowers, and W. A. Chaves. 2019. Identifying effective climate change education strategies: a systematic review of research. Environmental Education Research 25:791-812. https://doi.org/10.1080/135046$\underline{22.2017 .1360842}$

Murthy, M. S. R., H. Gilani, B. Karky, E. Sharma, M. Sandker, U. A. Koju, S. Khanal, and M. Poudel. 2017. Synergizing community-based forest monitoring with remote sensing: a path to an effective REDD+ MRV system. Carbon Balance \& Management 12:19. https://doi.org/10.1186/s13021-017-0087-8

Naughton-Treves, L., and K. Wendland. 2014. Land tenure and tropical forest carbon management. World Development 55:1-6. https://doi.org/10.1016/j.worlddev.2013.01.010

Newman, G., M. Chandler, M. Clyde, B. McGreavy, M. Haklay, H. Ballard, S. Gray, R. Scarpino, R. Hauptfield, D. Mellor, and J. Gallo. 2017. Leveraging the power of place in citizen science for effective conservation decision making. Biological Conservation 208:55-64. https://doi.org/10.1016/j.biocon.2016.07.019

Oldekop, J. A., N. K. Truelove, S. Villamarín, and R. F. Preziosi. 2012. Information flows in community-based monitoring exercises in the Ecuadorian Amazon. International Journal of Zoology 2012:980520. https://doi.org/10.1155/2012/980520

Pantoja, M. C., E. L. Costa, and A. Postigo. 2009. A presença do gado em Reservas Extrativistas: algumas reflexões. Revista Pós Ciências Sociais 6:115-130.

Pokorny, B., and P. Pacheco. 2014. Money from and for forests: a critical reflection on the feasibility of market approaches for the conservation of Amazonian forests. Journal of Rural Studies 36:441-452. https://doi.org/10.1016/j.jrurstud.2014.09.004

Pramova, E., and B. Locatelli. 2013. Guidebook on integrating community-based adaptation into REDD+ projects: lessons from Indonesia and the Philippines. CIFOR, Bogor, Indonesia. https:// doi.org/10.17528/cifor/004340

Pulhin, J. M., and W. H. Dressler. 2009. People, power and timber: the politics of community-based forest management. Journal of Environmental Management 91:206-214. https://doi.org/10.1016/ j.jenvman.2009.08.007

Randrianarison, H., J. Ramiaramanana, and F. Wätzold. 2017. When to pay? Adjusting the timing of payments in PES design to the needs of poor land users. Ecological Economics 138:168-177. https://doi.org/10.1016/j.ecolecon.2017.03.040

Ruiz-Mallén, I., and E. Corbera. 2013. Community-based conservation and traditional ecological knowledge: implications for social-ecological resilience. Ecology and Society 18(4):12. https://doi.org/10.5751/ES-05867-180412

Schmink, M., and M. Arteaga Gómez-García 2015. Under the canopy: gender and forests in Amazonia. Center for International Forestry Research, Bogor, Indonesia.
Schmink, M., A. Duchelle, J. Hoelle, F. Leite, M. V. d'Oliveira, J. Vadjunec J. Valentim, and R. Wallace. 2014. Forest citizenship in Acre, Brazil. Pages 31-47 in P. Katila, G. Galloway, W. de Jong, P. Pacheco, and G. Mery, editors. Forests under pressure: local responses to global issues. IUFRO World Series Volume 32. International Union of Forest Research Organizations, Vienna, Austria.

Schwartzman, S., and B. Zimmerman. 2005. Conservation alliances with indigenous peoples of the Amazon. Conservation Biology 19:721-727. https://doi.org/10.1111/j.1523-1739.2005.00695. $\underline{\mathrm{X}}$

Shanley, P., and C. López. 2009. Out of the loop: why research rarely reaches policy makers and the public and what can be done. Biotropica 41:535-544. https://doi.org/10.1111/j.1744-7429.2009.00561. $\underline{\mathrm{x}}$

Sikor, T., J. He, and G. Lestrelin. 2017. Property rights regimes and natural resources: a conceptual analysis revisited. World Development 93:337-349. https://doi.org/10.1016/j.worlddev.2016.12.032

Skutch, M., editor. 2011. Community forest monitoring for the carbon market: opportunities under REDD. Earthscan, London, UK.

Sugden, A., J. Fahrenkamp-Uppenbrink, D. Malakoff, and S. Vignieri. 2015. Forest health in a changing world. Science 349:800-801. https://doi.org/10.1126/science.349.6250.800

Sullivan, S. 2009. Green capitalism, and the cultural poverty of constructing nature as service-provider. Radical Anthropology $3: 18-27$.

Sullivan, T. K., and A. K. Syvertsen. 2019. Conservation leadership: a developmental model. Journal of Adolescent Research 34:140-166. https://doi.org/10.1177/0743558417752638

Thomas, R. E. W., T. Teel, B. Bruyere, and S. Lawrence. 2019. Metrics and outcomes of conservation education: a quarter century of lessons learned. Environmental Education Research 25:172-192. https://doi.org/10.1080/13504622.2018.1450849

To, P. X., W. H. Dressler, S. Mahanty, T. T. Pham, and C. Zingerli. 2012. The prospects for payment for ecosystem services (PES) in Vietnam: a look at three payment schemes. Human Ecology 40:237-249. https://doi.org/10.1007/s10745-012-9480-9

Tomich, T. P., P. Lidder, J. Dijkman, M. Coley, P. Webb, and M. Gill. 2019. Agri-food systems in international research for development: ten theses regarding impact pathways, partnerships, and program design, and priority-setting for rural prosperity. Agricultural Systems 172:101-109. https://doi.org/10.1016/j. agsy.2018.12.004

Trumbore, S., P. Brando, and H. Hartmann. 2015. Forest health and global change. Science 349:814-818. https://doi.org/10.1126/ science.aac6759

Vadjunec, J. M., C. V. A. Gomes, and T. Ludewigs. 2009. Landuse/land-cover change among rubber tappers in the Chico Mendes Extractive Reserve, Acre, Brazil. Journal of Land Use Science 4:249-274. https://doi.org/10.1080/17474230903222499

Vadjunec, J. M., and D. Rocheleau. 2009. Beyond forest cover: land use and biodiversity in rubber trail forests of the Chico 
Mendes Extractive Reserve. Ecology and Society 14(2):29. https:// doi.org/10.5751/ES-03010-140229

Western, D., and R. M. Wright, editors. 1994. Natural connections: perspectives in community-based conservation. Island, Washington, D.C., USA.

World Wildlife Fund (WWF). 2015. Guia informativo da gestão participativa na reserva extrativista Chico Mendes - Acre. WWFBrasil, Brasília, Brasil.

Wunder, S., A. Angelsen, and B. Belcher. 2014. Forests, livelihoods, and conservation: broadening the empirical base. World Development 64:S1-S11. https://doi.org/10.1016/j.

worlddev.2014.03.007

Zarin, D., J. Alavalapati, F. Putz, and M. Schmink, editors. 2004. Working forests in the neotropics: conservation through sustainable management? Columbia University Press, New York, New York, USA. https://doi.org/10.7312/zari12906 